\title{
Interpreting the Deposition Behavior of Polydisperse Surface-Modified Nanoparticles using QCM-D and Sand-Packed Columns
}

\author{
Revised and resubmitted to: \\ Environmental Engineering Science
}

April 2, 2014

IVAN R. QUEVEDO ${ }^{1}$, ADAM L.J. OLSSON ${ }^{1}$, RHETT J. CLARK ${ }^{2}$, JONATHAN G.C. VEINOT $^{2}$, NATHALIE TUFENKJI ${ }^{*}, 1$
${ }^{1}$ Department of Chemical Engineering, McGill University,
Montreal, Quebec H3A 2B2, Canada
${ }^{2}$ Department of Chemistry, University of Alberta,
Edmonton, Alberta T6G 2G2, Canada

Ivan R. Quevedo; E-mail: ivan.quevedo@mail.mcgill.ca

Adam L.J. Olsson; E-mail: adam.olsson@mail.mcgill.ca

Rhett Clark; E-mail: rhett@ualberta.ca

Jonathan Veinot; E-mail: jveinot@ualberta.ca

*Corresponding Author: Phone: (514) 398-2999; Fax: (514) 398-6678; E-mail nathalie.tufenkji@mcgill.ca 


\section{Abstract}

The rising use of surface-modified engineered nanoparticles (ENPs) will result in their increased presence in aquatic environments; hence, a better understanding of their environmental fate is needed. In this study, silicon nanocrystals (Si-NCs) capped with organic acids of varying alkyl-chain length were used as model functionalized ENPs. Particle deposition kinetics were evaluated using sand packed columns and a quartz crystal microbalance with dissipation monitoring (QCM-D). In general, an increase in solution ionic strength (IS) resulted in increased particle deposition in both columns and the QCM-D. However, the overall trends in Si-NC deposition with respect to alkyl-chain length differed in the two experimental systems, revealing how the system geometry can play a key role in defining the contribution of different particle retention mechanisms. To interpret these differences in the Si-NC deposition behavior, multiple characterization techniques were used: dynamic light scattering, nanoparticle tracking analysis, scanning ion occlusion sensing, and laser Doppler velocimetry. QCM-D also revealed insights into the influence of the particle surface coatings on particle stability. The ratio of the two QCM-D output parameters revealed that the rigidity of the particle-collector interfaces varied with the alkyl-chain length, whereby particles capped with longer alkyl chains were less rigidly attached to the silica surface. Moreover, it is shown that the interpretation of ENP deposition behavior using QCM-D is limited by the presence of large particle aggregates $(\geq$ $700 \mathrm{~nm}$ in this study) that do not fully couple to the QCM-D sensor. Under such conditions, QCMD measurements of ENP deposition must be interpreted with caution as the microbalance response cannot be directly considered as deposited mass. This study improves our understanding of the role surface modifiers and ENP aggregates play in ENP deposition kinetics in efforts to predict the transport and fate of ENPs in natural and engineered aquatic environments.

Key words: Silicon nanocrystal; engineered nanoparticle; saturated porous media; transport; quartz crystal microbalance; qNano; NTA; DLS 


\section{Introduction}

The unique physical and optical properties of engineered nanoparticles (ENPs) are being exploited for diverse applications such as biomedical imaging, solar cells, or electronic devices (Algar et al. 2011; Klaine et al. 2008). To target specific needs, ENPs are commonly coated with different organic molecules (e.g., surfactants, polymers, or polyelectrolytes) (Hotze et al. 2010; Phenrat et al. 2010). For instance, $\mathrm{TiO}_{2}$ nanoparticles stabilized with polyacrylic acid conjugated with antibodies can be used for molecular recognition (Kanehira et al. 2008). Amphiphilic polymers render quantum dots waterdispersible and ready for use in biological sensing and intracellular labeling (Algar et al. 2011). Likewise, polymeric coatings (e.g., carboxymethyl cellulose, polyvinylpyrrolidone and guar gum) improve the stability of reactive zerovalent iron nanoparticles (nZVI) and the capability of bimetallic FePd nanoparticles to degrade chlorinated hydrocarbons (Raychoudhury et al. 2012; Sakulchaicharoen et al. 2010). However, an increasing number of products containing surfacemodified ENPs (Roco et al. 2011) will likely result in their incidence in the environment (Westerhoff et al. 2013), and since different ENPs have exhibited toxic effects (Klaine et al. 2008), understanding their transport and fate is crucial for assessing their contamination potential (Petosa et al. 2010).

Silicon based nanocrystals (Si-NCs) are one example of ENPs that exhibit luminescent properties and are promising as biomedical tracers (O'Farrell et al. 2006; Park et al. 2009). However, despite the apparent innocuous properties of $\mathrm{Si}$, some studies with silicon based nanoparticles have revealed toxic effects related to their physicochemical properties (i.e., particle size, surface charge, and surface coating) (Choi et al. 2009; Fujioka et al. 2008; Ruizendaal et al. 2009). Because the eventual manufacturing of consumer products containing surface-modified silicon nanoparticles is imminent 
(www.nanotechproject.org), a clear understanding of the colloidal stability and mobility of siliconbased nanomaterials (i.e., Si-NCs) is needed to predict their fate in aquatic environments.

In general, the mobility of ENPs has been studied using water saturated columns packed with granular materials (e.g., quartz sand) representative of aquifer sediments or engineered (deep-bed) filtration systems (Petosa et al. 2010). In column transport experiments, the extent of ENP retention is evaluated by monitoring the influent and effluent particle concentrations, and the results are commonly interpreted using clean-bed colloid filtration theory (Yao et al. 1971). Several studies of ENP transport in packed columns report an enhanced mobility of surface-modified ENPs due to the electrosteric stabilization imparted by the polymers or polyelectrolytes used to coat them (Mitzel and Tufenkji 2014; Petosa et al. 2012; Phenrat et al. 2010). Nonetheless, generalization to the myriad of surface modified ENPs introduced into the market every year (Roco et al. 2011) is complex, since the afforded level of electrosteric stability is associated to the properties of the molecules used (i.e., molecular weight, chemistry, adsorbed mass, density, extended layer thickness) (Phenrat et al. 2010). Thus, a better mechanistic understanding of the role surface modifiers play is needed to more accurately predict the transport and fate of ENPs in natural and engineered aquatic environments.

The quartz crystal microbalance with dissipation monitoring (QCM-D) is another useful technique for evaluating the deposition behavior of ENPs on model aquifer grain surfaces (e.g., $\mathrm{SiO}_{2}$, $\mathrm{Fe}_{2} \mathrm{O}_{3}$ or $\mathrm{Al}_{2} \mathrm{O}_{3}$ ) (Chen and Elimelech 2006; Lin and Wiesner 2012; Liu et al. 2012; Quevedo and Tufenkji 2009). Briefly, as particles deposit onto the QCM sensor, an increase in mass on the collector surface results in a measurable decrease in the crystal's resonance frequency (i.e., negative frequency shifts) (Sauerbrey 1959). Additionally, dissipative energy losses, induced by the deposited mass, are 
measured in terms of oscillation decay time. Whereas the applicability of QCM-D as a mass sensor to assess the deposition kinetics of ENPs is well known (Chen and Elimelech 2006; Fatisson et al. 2010; Quevedo and Tufenkji 2009), it was only recently shown that the ratio of the two QCM-D output parameters (dissipation/frequency) can be used to better understand the conformation of the surface coatings on deposited particles (Quevedo et al. 2013). Namely, the dissipation/frequency ratio revealed whether the conformation of a polyelectrolyte (i.e., polyacrylic-acid derivative) used to coat a $\mathrm{CdTe}$ QD was extended or compressed upon deposition onto alumina surfaces.

Regardless of the experimental technique utilized (e.g., column studies or QCM-D), nanoparticle deposition kinetics are generally dependent on the water chemistry (e.g., electrolyte species, ionic strength, and $\mathrm{pH}$ ) as well as collector and particle surface properties (Petosa et al. 2010). However, changes in water chemistry often lead to particle aggregation, which can be challenging to interpret (Domingos et al. 2009; Petosa et al. 2010). For instance, the retention of particle aggregates in packed granular matrices may increase due to deposition in the secondary energy minimum of the particlecollector interaction energy profile (Hahn et al. 2004; Pelley and Tufenkji 2008; Saleh et al. 2008) or physical straining in pore spaces that are too small to allow passage of the aggregates (Bradford et al. 2007; Petosa et al. 2012). Likewise, in QCM-D experiments, the deposition of aggregated ENPs might not always be straightforward to interpret using the conventional approach of mass loading (Fatisson et al. 2009; Lin and Wiesner 2012; Liu et al. 2012; Pomorska et al. 2010). For instance, positive frequency shifts associated with large particles or ENP-aggregates attached to the sensor via weak bridges have been reported (Fatisson et al. 2009; Pomorska et al. 2010), and this atypical response appears to be linked to the size of the particle aggregate (Pomorska et al. 2010). Hence, laboratory 
studies to assess the transport and deposition of ENPs in packed-bed columns and QCM-D require an appropriate physicochemical characterization to adequately interpret the results.

In this study, we have systematically evaluated and compared the deposition behavior of silicon nanocrystals (Si-NCs) as a model surface-modified ENP, using: (i) laboratory-scale columns packed with quartz sand, and (ii) QCM-D with $\mathrm{SiO}_{2}$ coated crystals (as a model sand surface). Both techniques were used to determine the deposition kinetics of surface-modified Si-NCs over a broad range of environmentally relevant solution chemistries, including variations in ionic strength (IS) and ion valence $\left(\mathrm{K}^{+}, \mathrm{Ca}^{2+}\right)$. The Si-NCs were modified with carboxylic acids having different chain lengths, as an increase in carbon chain length has been found to improve their colloidal stability in aqueous suspensions (Clark et al. 2010). Various techniques were also used to characterize the physicochemical properties of the Si-NCs over the range of water chemistries examined, including laser Doppler velocimetry to evaluate particle electrophoretic mobility, and dynamic light scattering (DLS), nanoparticle tracking analysis (NTA) and scanning ion occlusion sensing (SIOS) to evaluate particle and aggregate sizes.

\section{Experimental Protocols}

Preparation of Si-NC suspensions

Si-NCs were prepared and functionalized with carboxylic acids of different alkyl-chain lengths: propionic acid $\left(\mathrm{C}_{3}\right)$, heptanoic acid $\left(\mathrm{C}_{7}\right)$ and undecanoic acid $\left(\mathrm{C}_{11}\right)$ and dispersed in deionized water (DI) as described in the supplementary information. A systematic characterization of the 
functionalized Si-NCs by infrared spectroscopy (FTIR) and X-Ray photoelectron spectroscopy has proven that all the carboxylic acids are attached to the particle surface (Clark et al. 2010). Si-NC stock suspensions were diluted to a working concentration of $20 \mathrm{mg} / \mathrm{L}$ or $200 \mathrm{mg} / \mathrm{L}$ in electrolytes of varying IS (1-100 $\mathrm{mM} \mathrm{KCl}$ or $1-3 \mathrm{mM} \mathrm{CaCl}_{2}$ ) for transport experiments in packed bed columns or QCMD, respectively. Suspensions were adjusted to $\mathrm{pH} 5$ (using $\mathrm{HCl}$ ), and equilibrated for $2 \mathrm{hrs}$ at $9^{\circ} \mathrm{C}$ and then at room temperature for 30 min prior to each experiment. All chemicals used to prepare solutions were of analytical grade.

Electrokinetic characterization of Si-NCs in electrolyte

Laser Doppler velocimetry (ZetaSizer Nano, Malvern) was used to evaluate the electrophoretic mobility (EPM) of Si-NCs within the range of IS. EPM measurements were repeated using at least three different samples (prepared on different days) using disposable capillary cells at $20 \pm 0.2^{\circ} \mathrm{C}$. The electrical field $(E)$ was adjusted between 5 and $10 \pm 0.1 \mathrm{~V} / \mathrm{m}$. For comparative purposes, measured EPMs were converted to zeta potentials using the Henry equation and the expression for the retardation effect proposed by Ohshima (1994).

Sizing of Si-NCs in electrolyte

Dynamic light scattering (DLS; number mean) (ZetaSizer Nano, Malvern) and nanoparticle trajectory analysis (NTA) (LM10-HS Nanoparticle Analysis System, Nanosight) were used to determine the hydrodynamic diameters of the Si-NCs suspended in electrolyte prior to each transport experiment. For NTA measurements, the mean square displacements of single particles were determined by tracking the scattered light, followed by analysis using the software (NanoSight v.2.2.), 
where each data point represents the average of at least 150 counted particles. At selected conditions, SIOS was used to confirm the size of the Si-NCs in electrolyte (qNano, IZON Science). In SIOS, a Coulter-type sensor allows single particle measurements as colloidal particles are driven through pores of known size (Vogel et al. 2011). Membranes with different pore sizes $\left(\mathrm{NP}_{100}, \mathrm{NP}_{200}\right.$, and $\left.\mathrm{NP}_{400}\right)$ were mounted on the instrument and the translocation of Si-NCs through the stretched pores was detected as a result of changes in the background current (Vogel et al. 2011). Calibration with standard polystyrene latex beads of known sizes allowed the determination of the size of Si-NCs used in this study, following the procedure suggested by the vendor (IZON Science). In all cases, results are presented as the mean of size measurements conducted in triplicate.

\section{Transport experiments in packed-bed columns}

Experiments were conducted with $1 \mathrm{~cm}$ (internal diameter) glass chromatography columns (10/20, Amersham Biosciences, Piscataway, NJ) packed with high purity quartz sand. Prior to use, the sand was sieved with Nylon sieves (U.S. standard mesh sizes 50 and 70, 300 and $212 \mu \mathrm{m}$ openings, respectively) to obtain a sand sample having an average grain diameter $\left(d_{c}\right)$ of $256 \mu \mathrm{m}$. The sand was cleaned according to the procedure described previously (Pelley and Tufenkji 2008). Before each transport experiment, the required mass of sand was soaked in electrolyte for at least $16 \mathrm{hrs}$. To ensure uniform packing, sand was wet packed into the glass column using gentle vibration yielding a packedbed porosity $(\varepsilon)$ of 0.38 . The final height of the packed bed was $4 \pm 0.2 \mathrm{~cm}$. To condition the packed columns, 10 pore volumes (PVs) of background electrolyte (i.e., $\mathrm{KCl}$ or $\mathrm{CaCl}_{2}$ ) were pumped at a constant approach velocity of $1.06 \times 10^{-4} \mathrm{~m} / \mathrm{s}$ prior to the injection of Si-NCs. In all experiments, 8 
$\mathrm{mL}$ of each Si-NC suspension (equivalent to 6.6 PVs) were injected into the packed column. The effluent concentrations $(C)$ of fluorescent $\mathrm{Si}-\mathrm{NCs}$ (i.e., $\mathrm{C}_{7}$ and $\mathrm{C}_{11}$ ) were monitored in real time with a spectrofluorometer (Fluoromax-4, Jobin-Yvon Horiba) (EX/EM settings were: 350/603 for the $\mathrm{C}_{7}$, and 350/611 for $\left.C_{11}\right)$. The effluent concentration of the non-fluorescent Si-NC $\left(C_{3}\right)$ was monitored with a UV-visible spectrophotometer (Hewlett Packard 8453) (at a wavelength of $250 \mathrm{~nm}$ ) and, under selected conditions, confirmed by ICP-OES (see Supplementary Information). The concentrations of the influent suspensions $\left(C_{0}\right)$ were the same as those used for characterization of the particles. The absorbance or fluorescence of the injected suspensions was determined by bypassing the column apparatus. Si-NC transport experiments were conducted over a wide range of solution IS, using both monovalent $(\mathrm{KCl})$ and divalent salts $\left(\mathrm{CaCl}_{2}\right)$ and conducted in duplicate for each condition.

Interpretation of transport experiments in packed-bed columns

The results from sand-packed column experiments were quantitatively compared by determining the particle attachment efficiency $(\alpha)$ using colloid filtration theory (CFT) (Yao et al. 1971) as follows:

$$
\alpha=-\frac{2}{3} \frac{d_{c}}{(1-\varepsilon) L \eta_{0}} \ln \left(\frac{C}{C_{0}}\right)
$$

where $d_{c}$ is the average diameter of the sand grains, $\epsilon$ is the porosity of the porous medium, and $L$ is the packed column length. The value of $C / C_{0}$ represents the normalized column effluent particle concentration obtained by numerical integration of each particle breakthrough curve. Values of the 
predicted single-collector contact efficiency $\left(\eta_{0}\right)$ for each experimental condition were determined using the correlation developed by Tufenkji and Elimelech (2004).

Deposition of Si-NCs onto $\mathrm{SiO}_{2}$ measured by QCM-D

Deposition rates of Si-NCs onto $\mathrm{SiO}_{2}$-coated sensors (QSX-303, Q-Sense AB, Gothenburg, Sweden) were determined using a QCM-D (E4, Q-Sense AB). When the $5 \mathrm{MHz}$ AT-cut crystals are mounted in the QCM-D flow modules, the injected flow is parallel to the flat $\mathrm{SiO}_{2}$ surface. Si-NC deposition experiments were repeated using at least three different samples prepared on different days and conducted as follows: a peristaltic pump (Reglo-Digital IPC-N 4, Ismatec) was used to first inject DI $(50 \mu \mathrm{L} / \mathrm{min})$ to obtain a stable baseline. Next, the background electrolyte solution of interest was injected into the flow module, followed by a Si-NC suspension in the same electrolyte solution for at least 20 min. After each experiment, the $\mathrm{SiO}_{2}$ crystals, QCM-D chambers, and tubing were cleaned following the protocol suggested by Q-Sense. First, the instrument was rinsed with $20 \mathrm{~mL}$ of $2 \%$ Hellmanex (Fisher Scientific) and $30 \mathrm{~mL}$ of DI. The crystals were further cleaned by soaking in $2 \%$ Hellmanex overnight, rinsed with DI, dried under $\mathrm{N}_{2}$ and then exposed to UV/ozone treatment for 10 min prior to any additional measurement. 


\section{Interpretation of $Q C M-D$ deposition experiments}

The QCM-D is commonly referred to as a mass sensor because changes in the resonance frequency $(-\nabla f)$ of a quartz crystal are proportional to the deposited mass $(\bigotimes m)$ per unit area. Dissipative energy losses (dissipation shift, $₫ D$ ) of the deposited film are deduced from the oscillation decay times of each oscillation cycle. . In the case of rigidly adsorbed films $(\nabla D \sim 0)$, frequency shifts $\left(-\nabla f_{(\mathrm{n})}\right)$ are proportional to the deposited mass $(\mathbb{\otimes} m)$, as described by the Sauerbrey relationship (1959):

$$
-\Delta f_{(\mathrm{n})}=-\frac{\Delta f_{n}}{n}=\frac{\Delta m}{C}
$$

In eq. $2, C$ is the mass sensitivity constant, equal to $17.7 \mathrm{ngcm}^{-2} \mathrm{~Hz}^{-1}$ for a $5 \mathrm{MHz}$ crystal and $n$ is the resonance overtone number $(n=3,5,7,9,11,13)$. Note that the frequency shift obtained from QCM-D (Q-Sense) is already normalized (i.e., $\left.\Delta f_{(n)}=\Delta f_{n} / n\right)$. When the Sauerbrey relation (1959) is valid, the rate at which frequency shift changes during a given time period $\left(-f_{(n)}\right.$ slope, eq. 3$)$ describes the rate at which mass is deposited on the $\mathrm{SiO}_{2}$ surface $\left(r_{\mathrm{d}}\right)$ :

$$
r_{\mathrm{d}}=-f_{(n) \_ \text {slope }}=-\frac{d \Delta f_{(n)}}{d t}
$$

As discussed later in the manuscript, this is a valid assumption if the normalized frequency shifts at all the overtones are negative (i.e., $\left.\Delta f_{(3)}, \Delta f_{(5)}, \ldots \Delta f_{(13)} \leq 0\right)$. Conversely, positive frequency shifts at high overtones $(n)$ are a clear indication of a "coupled resonance" type response, which is linked to the bond strength between particles and collector, but cannot be interpreted as deposited mass (Olsson et al. 2012; Pomorska et al. 2010).

\section{Results and Discussion}




\section{Characterization of capped Si-NCs in electrolyte}

The electrophoretic mobility (EPM) and size of the studied Si-NCs were assessed prior to each transport and deposition experiment in the presence of monovalent $(\mathrm{KCl})$ and divalent $\left(\mathrm{CaCl}_{2}\right)$ salts (Table 1). All the Si-NCs studied are negatively charged under the experimental conditions $(\mathrm{pH} 5$, solution IS) due to the presence of carboxyl groups in the surface cappings $\left(\mathrm{C}_{3}, \mathrm{C}_{7}, \mathrm{C}_{11}\right)$. The experimental data (Table 1) reveals that as the IS increases, compression of the electrical double layer results in lower EPM values (Elimelech et al. 1995). Between 1 and $100 \mathrm{mM} \mathrm{KCl,} \mathrm{more} \mathrm{important}$ variations in the EPM values are observed for Si-NCs capped with $\mathrm{C}_{3}$ (i.e., EPM varies between -2.3 and $-0.7 \mu \mathrm{m} \cdot \mathrm{cm} / \mathrm{V} \cdot \mathrm{s})$, as compared to particles capped with the longest chain length, namely $\mathrm{C}_{11}$ (where EPM only varies between -1.1 and $-0.7 \mu \mathrm{m} \cdot \mathrm{cm} / \mathrm{V} \cdot \mathrm{s}$ ). Variations in the electrokinetic properties of surface-modified ENPs as a function of IS are commonly associated with the properties of the capping ligands at the particle surface (Phenrat et al. 2010).

In divalent salt $\left(\mathrm{CaCl}_{2}\right)$, the $E P M$ changes from -2.0 to $-0.7 \mu \mathrm{m} \cdot \mathrm{cm} / \mathrm{V} \cdot \mathrm{s}$ for the $\mathrm{C}_{3}$, from -1.3 to $-0.4 \mu \mathrm{m} \cdot \mathrm{cm} / \mathrm{V}$.s for the $\mathrm{C}_{7}$ and from -0.9 to $-0.03 \mu \mathrm{m} \cdot \mathrm{cm} / \mathrm{V} \cdot \mathrm{s}$ for the $\mathrm{C}_{11}$ when the IS increases from 0.3 to $3 \mathrm{mM} \mathrm{CaCl}_{2}$. In Table 1, EPM measurements are converted to zeta potential, using the particle sizes $\left(d_{\mathrm{p}}\right)$ obtained by DLS, and these values are used later in this manuscript to interpret the deposition results within the context of DLVO theory of colloidal stability. 
Table 1. Electrokinetic properties and particle size $\left(d_{\mathrm{p}}\right)$ of Si-NCs as a function of solution IS in $\mathrm{KCl}$ or $\mathrm{CaCl}_{2}$ at $\mathrm{pH} 5$ determined using different techniques. Data represents the mean diameter \pm standard deviation.

\begin{tabular}{|c|c|c|c|c|c|c|c|c|c|}
\hline \multirow{2}{*}{ electrolyte } & \multirow{2}{*}{$\begin{array}{l}\text { ionic } \\
\text { strength } \\
(\mathrm{mM}) \\
\end{array}$} & \multirow{2}{*}{ Si-NC } & \multirow{2}{*}{$\begin{array}{c}\text { electrophoretic } \\
\text { mobility } \\
(\mu \mathrm{m} . \mathrm{cm} / \mathrm{V} . \mathrm{s})\end{array}$} & \multirow{2}{*}{$\begin{array}{c}\text { zeta potential } \\
(\mathrm{mV}) \\
\end{array}$} & \multirow{2}{*}{ PDI } & \multicolumn{4}{|c|}{ particle size $\left(d_{\mathrm{p}}\right)$} \\
\hline & & & & & & & $\begin{array}{l}\mathrm{DLS} \\
\mathrm{nm})\end{array}$ & $\begin{array}{l}\text { NTA } \\
(\mathrm{nm})\end{array}$ & $\begin{array}{l}\text { SIOS } \\
(\mathrm{nm})\end{array}$ \\
\hline \multirow{5}{*}{$\mathrm{KCl}$} & 1 & \multirow{5}{*}{$\mathrm{C}_{3}$} & $-2.3 \pm 0.1$ & $-42 \pm 2$ & 0.32 & 86 & \pm 56 & \multirow{2}{*}{$72 \pm 4$} & \\
\hline & 10 & & $-2.0 \pm 0.2$ & $-29 \pm 2$ & 0.40 & 478 & \pm 151 & & \\
\hline & 30 & & $-1.2 \pm 0.1$ & $-17 \pm 2$ & 0.53 & 578 & \pm 221 & $253 \pm 33$ & \\
\hline & 50 & & $-0.9 \pm 0.1$ & $-13 \pm 2$ & 0.53 & 979 & \pm 460 & $245 \pm 189$ & $766 \pm 43$ \\
\hline & 100 & & $-0.7 \pm 0.1$ & $-10 \pm 1$ & 0.54 & 703 & \pm 261 & $278 \pm 245$ & $862 \pm 53$ \\
\hline \multirow{5}{*}{$\mathrm{KCl}$} & 1 & \multirow{5}{*}{$\mathrm{C}_{7}$} & $-1.8 \pm 0.2$ & $-37 \pm 5$ & 0.34 & 48 & \pm 14 & \multirow[t]{2}{*}{$97 \pm 47$} & \\
\hline & 10 & & $-1.6 \pm 0.1$ & $-25 \pm 1$ & 0.48 & 135 & \pm 36 & & \\
\hline & 30 & & $-0.6 \pm 0.1$ & $-8 \pm 2$ & 0.65 & 847 & \pm 185 & $179 \pm 42$ & \\
\hline & 50 & & $-0.7 \pm 0.2$ & $-9 \pm 2$ & 0.74 & 949 & \pm 308 & $163 \pm 85$ & $140 \pm 20$ \\
\hline & 100 & & $-0.7 \pm 0.1$ & $-11 \pm 2$ & 0.87 & 761 & \pm 146 & $362 \pm 174$ & $150 \pm 10$ \\
\hline \multirow{5}{*}{$\mathrm{KCl}$} & 1 & \multirow{5}{*}{$C_{11}$} & $-1.1 \pm 0.1$ & $-20 \pm 1$ & 0.23 & 92 & \pm 35 & \multirow[t]{2}{*}{$98 \pm 34$} & \\
\hline & 10 & & $-1.1 \pm 0.3$ & $-18 \pm 4$ & 0.26 & 70 & \pm 40 & & \\
\hline & 30 & & $-1.0 \pm 0.5$ & $-15 \pm 8$ & 0.29 & 69 & \pm 12 & $96 \pm 10$ & \\
\hline & 50 & & $-0.9 \pm 0.3$ & $-14 \pm 5$ & 0.16 & 85 & \pm 25 & $92 \pm 68$ & $140 \pm 16$ \\
\hline & 100 & & $-0.7 \pm 0.2$ & $-10 \pm 3$ & 0.26 & 122 & \pm 23 & $174 \pm 86$ & $155 \pm 8$ \\
\hline \multirow{3}{*}{$\mathrm{CaCl}_{2}$} & 0.3 & \multirow{3}{*}{$\mathrm{C}_{3}$} & $-2.0 \pm 0.1$ & $-37 \pm 3$ & 0.34 & 117 & \pm 10 & $140 \pm 6$ & \\
\hline & 1.5 & & $-1.2 \pm 0.1$ & $-18 \pm 2$ & 0.87 & 1125 & \pm 339 & $278 \pm 32$ & \\
\hline & 3 & & $-0.7 \pm 0.1$ & $-11 \pm 2$ & 0.72 & 1066 & \pm 125 & $268 \pm 70$ & \\
\hline \multirow{3}{*}{$\mathrm{CaCl}_{2}$} & 0.3 & \multirow{3}{*}{$C_{7}$} & $-1.3 \pm 0.4$ & $-18 \pm 6$ & 0.15 & 31 & \pm 9 & $62 \pm 13$ & \\
\hline & 1.5 & & $-0.4 \pm 0.2$ & $-5 \pm 3$ & 0.97 & 810 & \pm 273 & $135 \pm 5$ & \\
\hline & 3 & & $-0.6 \pm 0.1$ & $-9 \pm 1$ & 0.92 & 1246 & \pm 393 & $265 \pm 41$ & \\
\hline \multirow{3}{*}{$\mathrm{CaCl}_{2}$} & 0.3 & \multirow{3}{*}{$C_{11}$} & $-0.9 \pm 0.1$ & $-13 \pm 1$ & 0.31 & 97 & \pm 10 & $89 \pm 35$ & \\
\hline & 1.5 & & $-0.5 \pm 0.5$ & $-7 \pm 7$ & 0.79 & 481 & \pm 224 & $162 \pm 45$ & \\
\hline & 3 & & $0.0 \pm 0.7$ & $0 \pm 10$ & 0.67 & 930 & \pm 671 & $202 \pm 41$ & \\
\hline
\end{tabular}


Particle size plays an important role in the transport, fate, and bioavailability of ENPs in aquatic environments (Petosa et al. 2010). Hence, to interpret the observed transport and deposition behavior of the Si-NCs, an appropriate selection of size characterization methods is required (Domingos et al. 2009). It has been shown that the length of the ligand chain significantly influences the colloidal stability (i.e., aggregation) of Si-NCs in polar solvents. Clark et al. (2010) determined that the size of the "as synthesized" capped Si-NCs used here was on the order of $3 \mathrm{~nm}$, and after dispersion in DI, SiNCs capped with $\mathrm{C}_{3}$ and $\mathrm{C}_{7}$ experienced aggregation (Figure $S 1$ ). In Table 1, the mean diameters $\left(d_{\mathrm{p}}\right)$ for each Si-NC suspended in monovalent $(\mathrm{KCl})$ and divalent electrolytes $\left(\mathrm{CaCl}_{2}\right)$ using three different methods (i.e., DLS, NTA, and SIOS) are shown. DLS measurements show that the $d_{\mathrm{p}}$ of Si-NCs capped with $\mathrm{C}_{3}$ and $\mathrm{C}_{7}$ increases by one order of magnitude within the range of IS investigated (1-100 mM $\mathrm{KCl}$ ). In contrast, the particle capped with $\mathrm{C}_{11}$ is more stable over the range of IS. NTA measurements generally confirm the trends observed by DLS whereby Si-NCs capped with $\mathrm{C}_{3}$ and $\mathrm{C}_{7}$ exhibit larger $d_{\mathrm{p}}$ as compared to those capped with $\mathrm{C}_{11}$. Nonetheless, the mean hydrodynamic diameters obtained by NTA are typically smaller than those obtained by DLS (except for $\mathrm{C}_{11}$ suspended in $\mathrm{KCl}$ ), and these discrepancies are likely due to the interpretation of particle size with each technique. Whereas DLS measurements are influenced by the presence of small amounts of aggregates or dust particles (i.e., scattered light intensity is proportional to $d_{\mathrm{p}}{ }^{6}$ ), NTA tracks individual particles and the presence of a few aggregates in suspension is not expected to bias the results as strongly as in DLS (Domingos et al. 2009). However, because the resolution of NTA is limited by the refractive index of the material and larger particles or aggregates $(-1 \bigotimes \mathrm{m})$ are not tracked by this technique (Gallego-Urrea et al. 2011), the use of a third method is of interest to support the characterization of the Si-NCs (Bell et al. 2012; 
Domingos et al. 2009). SIOS is a recently introduced non-light scattering technique which promises to improve the size assessment of polydisperse samples based on the Coulter principle (Vogel et al. 2011). In SIOS, particles suspended in electrolyte pass through membranes with size tunable pores when a fixed electrical potential is applied. Changes in the ionic current as a result of particles traversing the pores are defined as "blockades" and their amplitude can be related to the size of the particle passing through (Vogel et al. 2011). In Table 1, mean sizes determined by SIOS at $100 \mathrm{mM} \mathrm{KCl}$ reveal significant aggregation for the particle capped with $\mathrm{C}_{3}\left(d_{\mathrm{p}} \sim 862 \mathrm{~nm}\right)$, and smaller sizes for $\mathrm{C}_{7}\left(d_{\mathrm{p}} \sim 150\right.$ $\mathrm{nm})$ and $\mathrm{C}_{11}\left(d_{\mathrm{p}} \sim 155 \mathrm{~nm}\right)$. Figure 1 shows a comparison of Si-NC size distributions measured at 100 $\mathrm{mM} \mathrm{KCl}$ using the three methods (DLS, NTA and SIOS) that may help to clarify the differences in the mean size of the suspensions (Table 1).
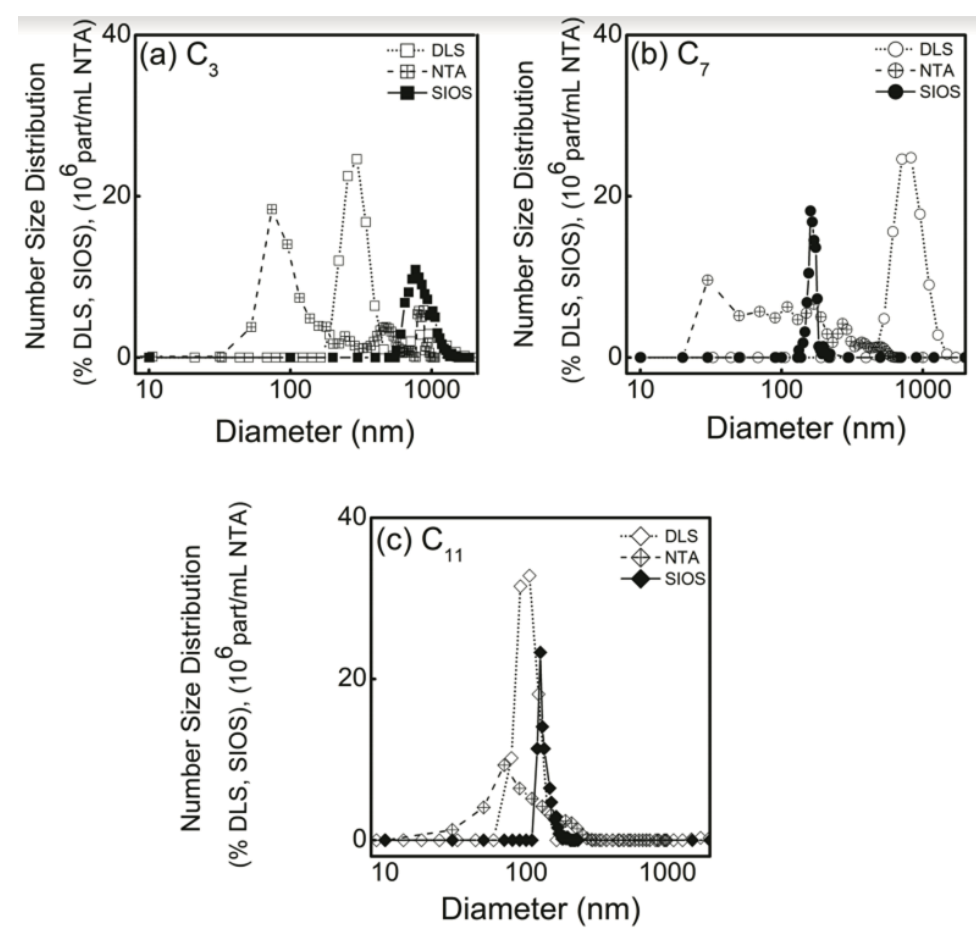

Figure 1 
In Figures $1 \mathrm{a}$ and $1 \mathrm{~b}$, Si-NCs capped with $\mathrm{C}_{3}$ and $\mathrm{C}_{7}$ exhibit broad size distributions and consequently, the mean sizes obtained are expected to be biased by the limitations mentioned above for the DLS and NTA techniques (Domingos et al. 2009; Gallego-Urrea et al. 2011). The particles capped with $\mathrm{C}_{11}$ (Figure 1c) exhibit normal distributions with comparable mean sizes for the ensemble of characterization techniques corroborating their stability in aqueous suspensions. These results are in agreement with previous studies (Bell et al. 2012; Vogel et al. 2011) where sizes determined by SIOS have been compared with different characterization techniques; namely DLS, NTA, and transmission electron microscopy (TEM) measurements.

DLS size measurements conducted with Si-NCs suspended in $\mathrm{CaCl}_{2}$ reveal that considerable particle aggregation occurs, regardless of the chain length of the capping ligand (Table 1). For instance, the presence of $1.5 \mathrm{mM} \mathrm{CaCl}_{2}$ seems sufficient to reach the critical coagulation concentration (CCC), which is supported by the large standard deviations observed at this IS. In $\mathrm{CaCl}_{2}, \mathrm{NTA}$ measurements do not appear to track particle aggregates, and SIOS measurements are not feasible at the studied range of IS, due to the low conductivity of the suspensions. The results obtained here are consistent with previous studies where considerable aggregation of carboxyl-modified ENPs was observed, even in the presence of low concentrations of divalent salt (Liu et al. 2012; Petosa et al. 2012; Quevedo and Tufenkji 2012). 
Transport of capped Si-NCs in saturated sand packed columns

Figure S2 shows representative particle breakthrough curves for experiments conducted with Si-NCs suspended in $\mathrm{KCl}$, and in Table 2 the normalized column effluent particle concentrations $\left(C / C_{0}\right)$ are reported as a function of IS. For all three Si-NCs, the measurements show a decrease in $C / C_{0}$ with increasing solution IS. However, the capping ligand with the longest chain $\left(C_{11}\right)$ seems to improve the mobility of Si-NCs up to a moderate salt concentration (30 mM IS). For instance, in experiments conducted at $30 \mathrm{mM} \mathrm{KCl}$, the particles capped with $\mathrm{C}_{11}$ exhibit lower retention ( 24\%) as compared to those capped with $\mathrm{C}_{3}(\sim 38 \%)$, and $\mathrm{C}_{7}(\sim 56 \%)$. Yet, at $100 \mathrm{mM} \mathrm{KCl}$, more than $50 \%$ of all the Si-NCs are retained. 
Table 2. Summary of experiments conducted in saturated quartz sand columns with $\mathrm{KCl}$ and $\mathrm{CaCl}_{2}$ at $\mathrm{pH} 5$.

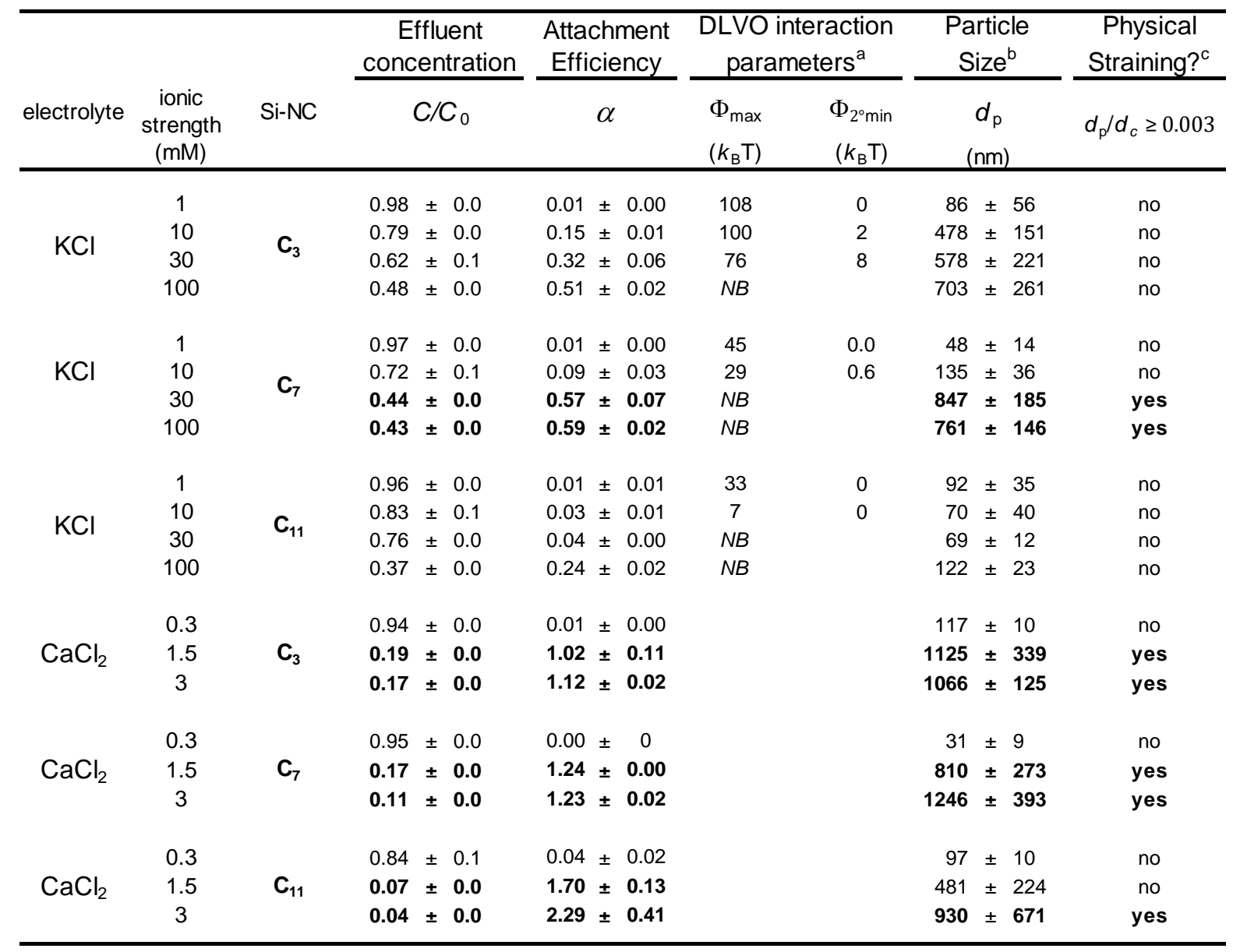

${ }^{a}$ Calculated classical DLVO interaction energy parameters $\left(\Phi_{\max }\right.$ and $\left.\Phi_{2^{\circ} \min }\right)$ reported in units of $k_{\mathrm{B}} \mathrm{T}$ for the Si-NCs interacting with quartz sand. To calculate the retarded VDW forces, a Hamaker constant of $1.92 \times 10^{-20} \mathrm{~J}$ was selected for the nanoparticle-water-quartz system (Senden and Drummond 1995), whereas for EDL interactions, constant-potential values were calculated using the zeta potential of the Si-NCs (Table 1) and the quartz sand in place of their respective surface potentials. The values of zeta potential used for the quartz sand were obtained from Redman et al. (2004). NB: No energy barrier.

${ }^{\mathrm{b}}$ The DLS measured particle sizes of the Si-NCs (Table 1) were used in the DLVO and straining calculations.

${ }^{c}$ The transport experiments were conducted in fine silica sand $\left(d_{c}=256 \unrhd \mathrm{m}\right)$, and straining may play a significant role in deposition when $d_{d} d d_{\mathrm{p}}$ is as low as 0.003 (Bradford et al. 2007). 
Figure 2 summarizes the calculated attachment efficiencies $(\alpha)$ for the surface-modified SiNCs. For the sake of clarity, the $\alpha$ values were determined using only the $d_{\mathrm{p}}$ obtained by DLS.
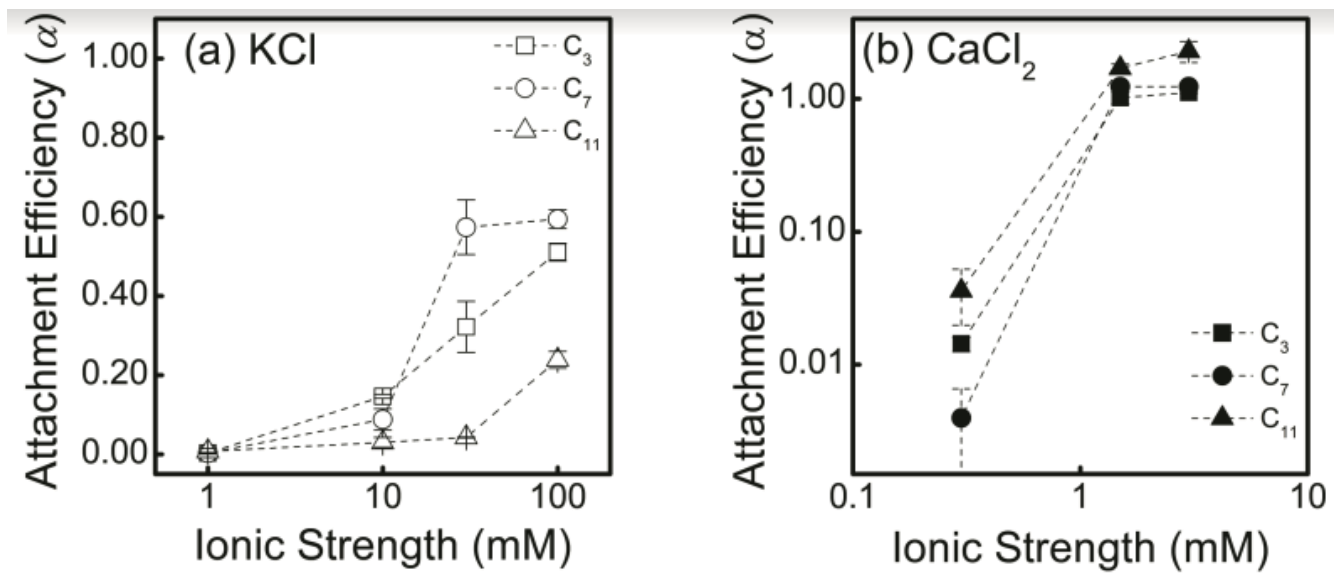

Figure 2

When suspended in $\mathrm{KCl}$ (Figure 2a), the $\alpha$ values for the Si-NCs increase significantly over the range of IS ( $\alpha$ values varied from 0.003 to 0.51 for the $\mathrm{C}_{3}$; from 0.002 to 0.59 for the $\mathrm{C}_{7}$; and from 0.01 to 0.24 for $\left.\mathrm{C}_{11}\right)$. Notably, $\alpha$ does not reach the theoretical mass-transfer limited value $(\sim 1)$ even at the maximum IS (100 mM) for any of the Si-NCs investigated. Based on the physicochemical characterization of the Si-NCs (Table 1), the EPM values decrease with increasing $\mathrm{KCl}$ concentration and, consequently, the Si-NCs experience less electrostatic repulsion as they approach the sand grain surface, thereby leading to increased particle deposition (Elimelech et al. 1995).

To determine the influence of divalent cations on the transport and deposition behavior of the Si-NCs, column experiments were also carried out with Si-NCs suspended in $\mathrm{CaCl}_{2}$. Unlike experiments conducted in $\mathrm{KCl}$, all the particles (i.e., $\mathrm{C}_{3}, \mathrm{C}_{7}, \mathrm{C}_{11}$ ) regardless of their alkyl-chain length, exhibit limited transport at low IS of the divalent salt solution (1.5-3 $\mathrm{mM} \mathrm{IS} \mathrm{CaCl}_{2}$ ) (Figure S3, Table 
1). These trends are likely linked to the ability of divalent cations (such as $\mathrm{Ca}^{2+}$ ) to bridge negatively charged groups on the Si-NC surface with the sand surface (Table 1). The drastic increase in $\alpha$ at 1.5

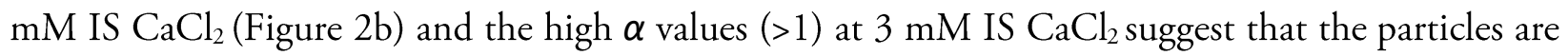
retained by an additional mechanism of physical straining in the packed column (Petosa et al. 2012; Tufenkji et al. 2004). Physical straining occurs when ENPs aggregate to sizes $\left(d_{\mathrm{p}}\right)$ that are larger than the pore spaces in the granular matrix (Bradford et al. 2007). As observed in Table 2, this hypothesis is supported by the physical properties of the particles (significant aggregation occurs at this IS), and the porous medium; namely the transport experiments were conducted in fine silica sand $\left(d_{\mathrm{p}} / d_{\mathrm{c}}\right.$ $\geq 0.003$ ), and the angularity of the sand grains is high (roundness factor $\sim 0.67$ ), which increases the likelihood of physical straining (Pelley and Tufenkji 2008; Petosa et al. 2012; Saleh et al. 2008; Tufenkji et al. 2004).

To better understand the mechanisms governing the particle deposition behavior in monovalent salt solution, interaction energy profiles between the particles and the grain surface were calculated using classical DLVO theory. Within the context of classical DLVO theory (which does not take into account the contribution of steric forces), solution chemistry and particle (or aggregate) size have important effects on the height of the repulsive energy barrier $\left(\Phi_{\max }\right)$, as well as on the depth

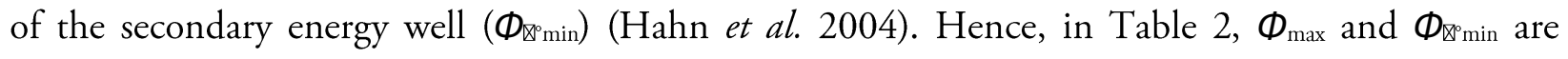
presented for each capped Si-NC as a function of $\mathrm{KCl}$ IS. The total interaction potentials were calculated as the sum of van der Waals forces (VDW) and electrical double layer interactions (EDL) using the linear superposition approximation and assuming the system can be approximated by a sphere-plate geometry (Elimelech et al. 1995). 
In Table 2, the calculated height of the interaction energy barrier $\left(\Phi_{\max }\right)$ for the three Si-NCs generally decreases as the IS of $\mathrm{KCl}$ increases. Likewise, each Si-NC exhibits greater retention in the sand-packed column with increasing $\mathrm{KCl}$ concentration (Figure 2a). Based on these simple, idealized classical DLVO calculations, the Si-NCs capped with the longest alkyl chains $\left(\mathrm{C}_{11}\right)$ are expected to deposit to a greater extent onto the sand surface than the $\mathrm{C}_{7}$, and the $\mathrm{C}_{7}$ are in turn expected to deposit more than the $\mathrm{C}_{3}$, for which greater energy barriers are predicted at any given IS. However, this is not always the case; e.g., in $10 \mathrm{mM} \mathrm{KCl}$, where $\alpha \mathrm{C}_{3}>\alpha \mathrm{C}_{7}>\alpha \mathrm{C}_{11}$. This observation can be attributed to three main factors: $(i)$ the particle capped with $\mathrm{C}_{3}$ forms fairly large aggregates and may thus deposit in a secondary energy well $\left(\Phi_{2^{\circ} \mathrm{min}}\right)$ at a separation distance greater than that of the energy barrier (Hahn et al. 2004) (Table 2), (ii) the larger $\mathrm{C}_{3}$ and $\mathrm{C}_{7}$ aggregates may be retained by physical straining, and (iii) the deposition of the Si-NCs capped with longer alkyl chains $\left(\mathrm{C}_{7}\right.$ and $\left.\mathrm{C}_{11}\right)$ is hindered by a repulsive steric force (which is not accounted for in the DLVO calculations). Interestingly, in $30 \mathrm{mM}$ $\mathrm{KCl}, \alpha \mathrm{C}_{7}>\alpha \mathrm{C}_{3}>\alpha \mathrm{C}_{11}$. At this IS, DLVO calculations predict no energy barrier for the $\mathrm{C}_{7}$ particle, yet the attachment efficiency does not reach the mass transport limited rate $(\sim 1)$ suggesting that the longer alkyl chain at the particle surface may be exerting some steric repulsion upon approach to the sand surface. The lower energy barriers predicted for the particle capped with $\mathrm{C}_{11}$ do not correlate with the low attachment efficiencies $(\alpha)$ measured in the transport experiments. These results suggest that the longest alkyl-chain $\left(\mathrm{C}_{11}\right)$ exerts significant steric repulsion thereby hindering particle deposition on the quartz sand (Hotze et al. 2010; Phenrat et al. 2010).

Certain surface modifiers (e.g., polymers, polyelectrolytes, surfactants) are known to inhibit the attachment of nanoparticles on sand or model silica surfaces as compared to their bare counterparts 
(Petosa et al. 2012; Phenrat et al. 2010; Quevedo and Tufenkji 2012). However, some studies have demonstrated that the stabilizing effects exerted by surface coatings are not always concordant (Lin $e t$ al. 2012; Saleh et al. 2008). Saleh et al. (2008) used packed column experiments to study the transport of nZVI capped with different surface modifiers. Whereas low molecular weight surfactants (sodium dodecyl benzene sulfonate) did not effectively enhance the mobility of nZVI, particles modified with high molecular weight polymers exhibited greater mobility due to electrosteric stabilizing effects. In another study, the transport of silver nanoparticles coated with different molecules (citrate, polyvinylpyrrolidone, and gum arabic) was studied in columns packed with glass beads (Lin et al. 2012). These authors observed an enhanced attachment of silver nanoparticles to glass surfaces when the hydrophobicity of the particle coatings and surfaces increased, despite the electrosteric repulsion afforded by the surface modifier. The results of our column study with the 3 Si-NCs suggest that the longest alkyl chain exerts considerable electrosteric repulsion upon approach to the sand surface; this mechanism also impairs the deposition of the $\mathrm{C}_{7}$ particle, but not to the same extent. Overall, the data show that a complex interplay of DLVO and non-DLVO forces and physicochemical processes contribute to the transport and deposition behavior of the surface-modified Si-NCs. 
Deposition of Si-NCs in QCM-D

In the second part of this study, $\mathrm{SiO}_{2}$-coated sensors mounted in a QCM-D were used as model collectors representing the surface of the sand grains used in the column experiments. Because the hydrodynamic conditions as well as the physicochemical properties of the collectors used (i.e., quartz sand vs. $\mathrm{SiO}_{2}$-coated flat sensors) differ between the columns and QCM-D experiments, the results obtained using the two systems are only qualitatively comparable. Values of the Si-NC deposition rate $\left(r_{\mathrm{d}}\right)$ when suspended in $\mathrm{KCl}$ or $\mathrm{CaCl}_{2}$ were determined from initial changes in frequency shifts ( $\left.\Delta f_{(\mathrm{n})}\right)$ as a function of time (eq. 3) (Figure $S 4$ and Table 3). The data are presented in terms of mass units (i.e., $\mathrm{ng} / \mathrm{cm}^{2} \cdot \mathrm{min}$ ) using the Sauerbrey relation (eq. 2) and frequency responses from the third overtone (i.e., $\left.\nabla f_{(3)}\right)$. Moreover, the dissipative energy losses $(\nabla D)$ at each experimental condition are presented as $\Delta D_{3} / \Delta f_{(3)}$ ratios (or, the equivalent - $\Delta D_{3 \_ \text {slope }}$ to $\Delta f_{(3) \_s l o p e}$ (Figure 3). The $\Delta D_{3} / \Delta f_{(3)}$ ratio provides useful insights about the particle-surface bond stiffness (Johannsmann et al. 2009), particle size (Olsson et al. 2013) and conformation of the polymeric coatings used to stabilize the particles (Quevedo et al. 2013). 
Table 3. Experimental deposition rates $\left(r_{\mathrm{d}}\right)$ from QCM-D measurements and particle size $\left(d_{\mathrm{p}}\right.$ - DLS) at the different experimental conditions. Data represent the mean \pm standard deviation.

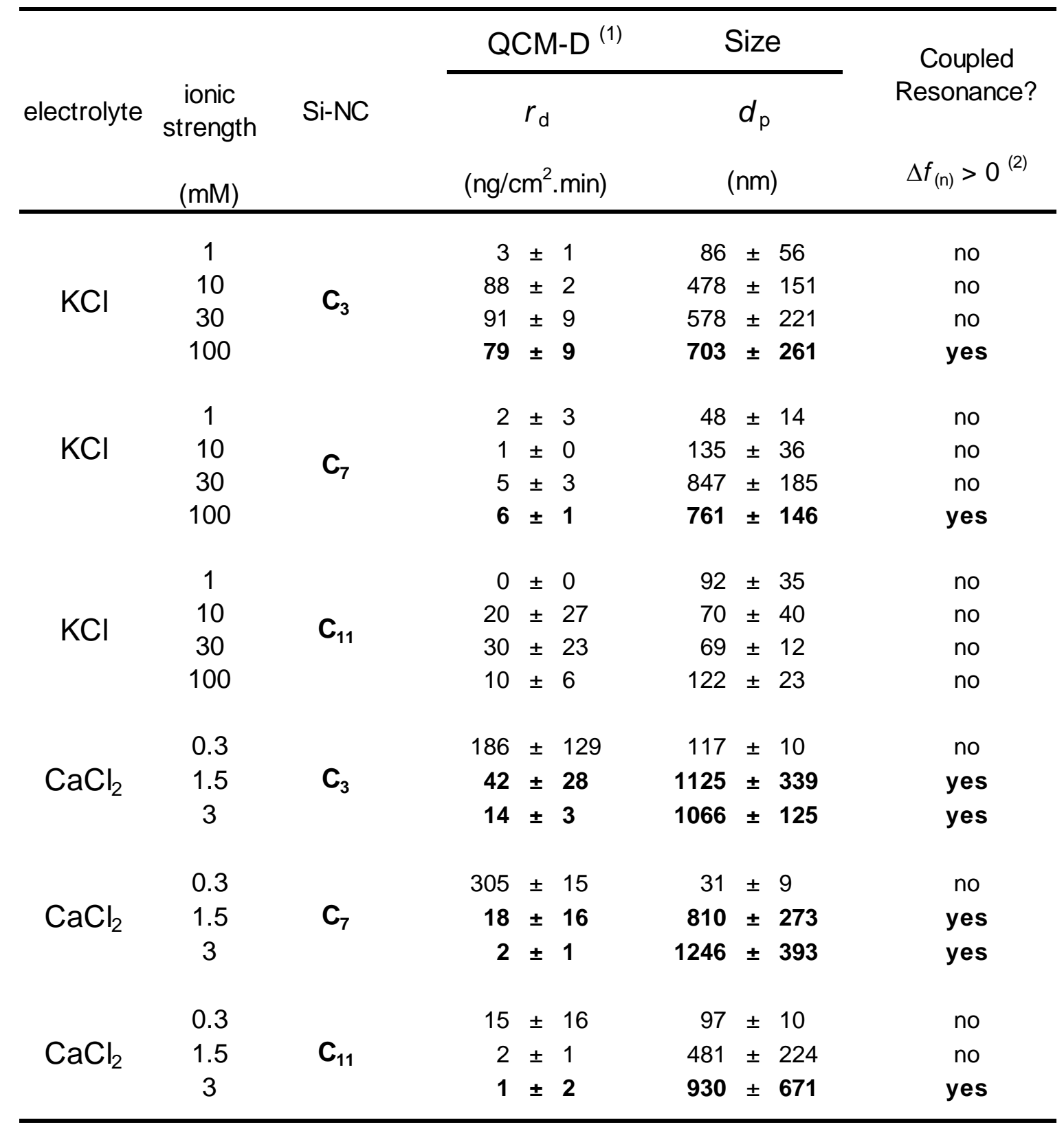

${ }^{(1)}$ In all cases, $r_{\mathrm{d}}$ was determined from $3^{\text {rd }}$ overtone measurements.

(2) Frequency shifts $\left(\bigotimes f_{(\mathrm{n})}\right)$ obtained at different overtones $(n=3,5,7,11,13)$ were compared and when positive responses were observed (i.e., coupled resonance), it has been indicated. 
In experiments conducted in $\mathrm{KCl}$, the Si-NCs capped with the longer alkyl chain lengths $\left(\mathrm{C}_{7}\right.$, $\mathrm{C}_{11}$ ) exhibit low deposition onto the $\mathrm{SiO}_{2}$ surface in the QCM-D, whereas the $\mathrm{C}_{3}$ particle deposition rate $\left(r_{\mathrm{d}}\right)$ increases with increasing salt concentration up to $30 \mathrm{mM}$ IS (Table 3). Between 1 and $30 \mathrm{mM}$ $\mathrm{KCl}, r_{\mathrm{d}}$ values for Si-NCs capped with $\mathrm{C}_{7}$ and $\mathrm{C}_{11}$ increase from 2 to $5 \mathrm{ng} / \mathrm{cm}^{2} \cdot \mathrm{s}$ and 0 to $30 \mathrm{ng} / \mathrm{cm}^{2} \cdot \mathrm{s}$, as compared to $\mathrm{C}_{3}$ (from 3 to $91 \mathrm{ng} / \mathrm{cm}^{2} \cdot \mathrm{s}$ ). The ratio $-D_{3 \text { sslope }} / f_{(3) \text { slope }}$ tends to decrease, which suggests that the particles are more rigidly deposited onto the $\mathrm{SiO}_{2}$ surface at the highest salt concentration. Namely, the calculated ratio $-D_{3 \text { _slope }} / f_{(3) \text { slope }}$ is closer to the limit of applicability proposed for the Sauerbrey model (Q-Sense) at the highest IS. The ratio $-D_{3_{-} \text {slope }} / f_{(3) \_s l o p e}$ also reveals that the particles capped with longer alkyl-chain cappings $\left(\mathrm{C}_{7}\right.$ and $\left.\mathrm{C}_{11}\right)$ dissipate more energy (higher $\left.-D_{3 \text { _slope }} / f_{(3) \text { _slope }}\right)$ and are thus less rigidly attached to the quartz sensor, as compared to the particles capped with the shortest alkyl chain capping $\left(\mathrm{C}_{3}\right)$. Notably, at the highest IS examined, larger error bars in $D_{(3) \_ \text {slope }} / f_{(3) \text { slope }}$ are observed for $\mathrm{C}_{3}$ as compared to the $\mathrm{C}_{7}$ and $\mathrm{C}_{11}$, and this behavior can be linked to the aggregated state of $\mathrm{C}_{3}$ at this condition (Table 3) (Quevedo et al. 2013).

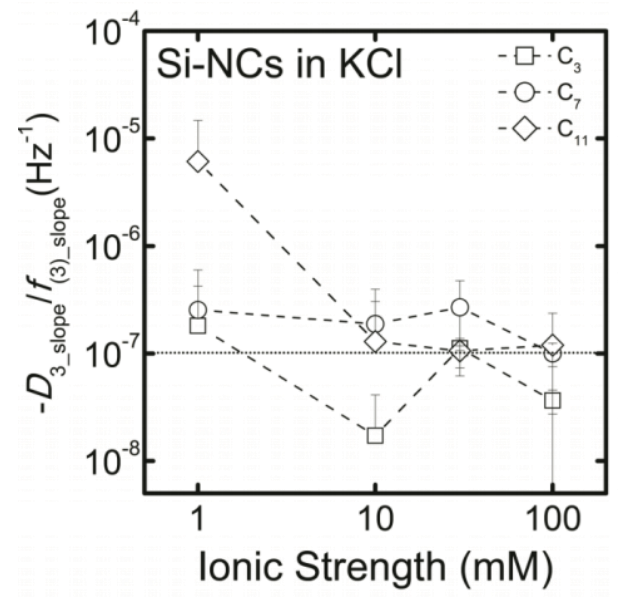

Figure 3 
Interestingly, when comparing the deposition behavior of the Si-NCs using the two different experimental systems (QCM-D and packed columns), different trends in deposition behavior are observed (Figure 2 and Table 3, respectively). In the packed column (Figure 2a), the particle capped with $\mathrm{C}_{7}$ experienced greater retention than the $\mathrm{C}_{3}$ and $\mathrm{C}_{11}$ (at 30 and $100 \mathrm{mM} \mathrm{KCl}$ ). This observation can be attributed to the important contribution of physical straining in the retention of the aggregated $\mathrm{C}_{7} \mathrm{Si}-\mathrm{NC}$ in the packed granular matrix; this mechanism is absent in the QCM-D where particles deposit onto a flat surface (Table 3). Differences in deposition behavior can also be observed in $\mathrm{CaCl}_{2}$ experiments (Figure 2b, and Table 3). All the Si-NCs reach the theoretical maximum deposition rate at $1.5 \mathrm{mM} \mathrm{CaCl}_{2}$ in the packed columns $(\alpha=1)$; however, they exhibit much lower deposition rates in the QCM-D when suspended in the same electrolyte. Here again, the observed differences can be attributed to the different controlling mechanisms in each experimental system (i.e., physical straining of larger aggregates in the column vs. reduced convective-diffusive transport and stronger bonding of those same aggregates to the collector surface in QCM-D). This latter concept will be discussed in more detail further in the manuscript.

QCM-D experiments conducted with particles suspended in $\mathrm{CaCl}_{2}$ (Table 3) show that the $r_{\mathrm{d}}$ values are generally higher in the presence of the divalent cation, likely due to $\mathrm{Ca}^{2+}$ bridging between negatively charged groups on the surface of the Si-NCs and the QCM crystal surface. However, in

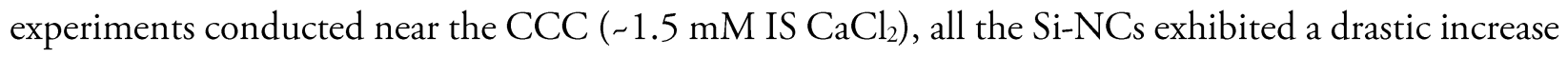
in their size $\left(d_{p}\right)$, and a drastic decrease in deposition rate is observed as compared to experiments conducted at $0.3 \mathrm{mM} \mathrm{IS} \mathrm{CaCl}_{2}$ (Table 3). In experiments conducted in $\mathrm{KCl}$ at the maximum IS (100 $\mathrm{mM} \mathrm{KCl}$ ), we also observe a decrease in $r_{\mathrm{d}}$ for particles capped with $\mathrm{C}_{3}$ and $\mathrm{C}_{7}$, as compared to 
experiments conducted at $30 \mathrm{mM} \mathrm{KCl}$ (Table 3). In agreement with these results, other QCM-D studies have reported that when particle aggregation is highly favorable, a lessened convective-diffusive transport of aggregated particles to the surface can result in lower measured $r_{\mathrm{d}}$ values (Chen and Elimelech 2006; Quevedo et al. 2013; Quevedo and Tufenkji 2009). To better understand this phenomenon, experimental deposition rates $\left(r_{\mathrm{d}}\right)$ were normalized by the theoretical particle deposition rate $\left(r_{\mathrm{d}}^{S \mathrm{SL}}\right)$ based on purely convective-diffusive transport (Adamczyk and van de Ven 1981) (Figure 4). At low solution IS (where repulsive electrostatic interactions predominate), $r_{\mathrm{d}}$ is expected to be significantly lower than the theoretical mass transport limited deposition rate $\left(r_{\mathrm{d}}^{\mathrm{SL}}\right)$, but as the IS increases, the energy barriers between the $\mathrm{Si}-\mathrm{NCs}$ and the $\mathrm{SiO}_{2}$ surface are expected to decline and $r_{\mathrm{d}} / r_{\mathrm{d}}{ }^{\mathrm{SL}}$ should approach unity. However, in experiments conducted with highly aggregated Si-NCs; namely, at $100 \mathrm{mM} \mathrm{KCl}$ and at $1.5 \mathrm{mM} \mathrm{CaCl}_{2}$ (Figures $4 \mathrm{a}$ and $4 \mathrm{~b}$, respectively), we observe that $r_{\mathrm{d}}$ in the absence of energy barriers is considerably lower than the theoretical deposition rates $\left(r_{\mathrm{d}} / r_{\mathrm{d}}{ }^{\mathrm{SL}}<<1\right)$.
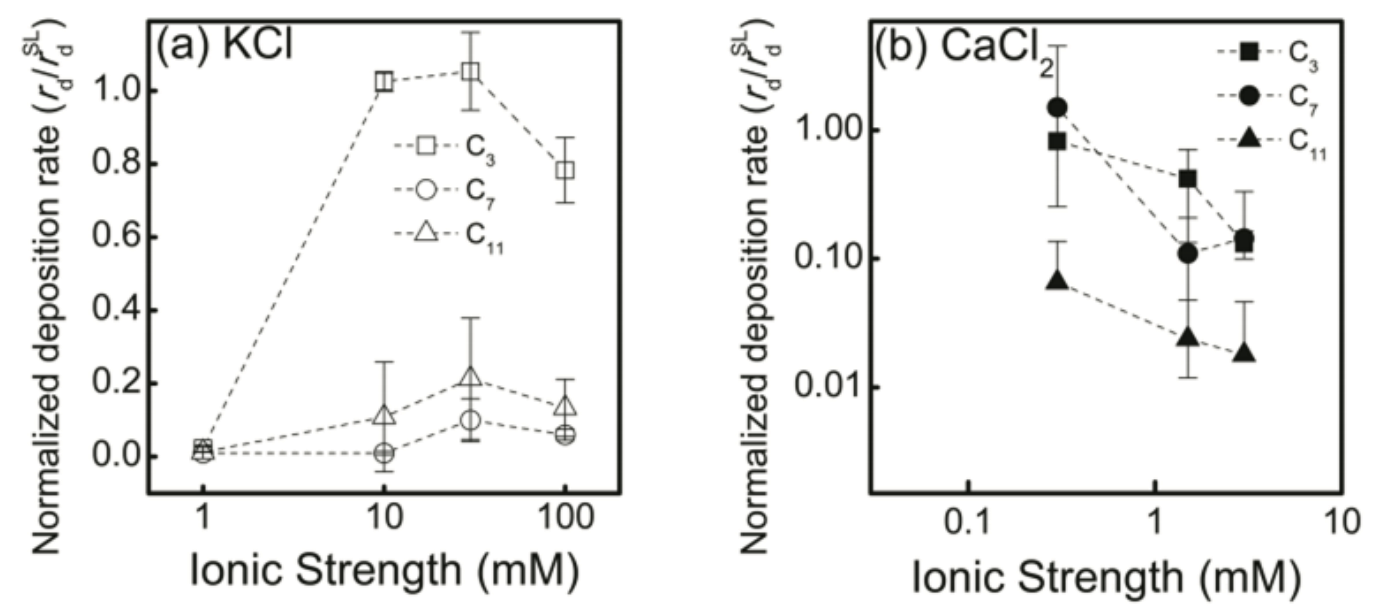

Figure 4 
The interpretation of aggregated nanoparticle systems using QCM-D has proven to be challenging (Lin and Wiesner 2012; Liu et al. 2012; Pomorska et al. 2010), and in some cases, positive frequency shifts have been reported (Fatisson et al. 2009; Pomorska et al. 2010), which are counterintuitive to the principle of QCM-D as a sensitive mass sensor. Positive frequency shifts can be explained in the context of "coupled resonance theory" (Dybwad 1985). In brief, $\Delta f_{(\mathrm{n})}$ can be either negative or positive depending on how well the particle couples to the oscillation of the sensor during the measurement. Whereas firmly coupled particles decrease the crystal resonance frequency as per conventional mass-loading theory (i.e., inertial loading), weakly coupled particles possess a resonance of their own that, depending on the bond stiffness, might increase the crystal resonance frequency (i.e., elastic loading) (Pomorska et al. 2010). The latter case has been shown to occur when micron-sized particles deposit on a QCM sensor (Berglin et al. 2008; Fatisson et al. 2009; Olsson et al. 2012), and in some instances, a transition from inertial loading (negative frequency shifts) at low overtones to elastic loading (positive frequency shifts) at high overtones can be observed along with a maximum in the dissipation factor $\left(\Delta D_{\mathrm{n}}\right)($ Olsson et al. 2012; Pomorska et al. 2010). In Figure 5a and 5b, we have plotted the frequency and dissipation response, at different overtones $(n)$ for Si-NCs capped with $\mathrm{C}_{11}$ in $\mathrm{CaCl}_{2}$. The results can be compared with the particle size distributions and $d_{\mathrm{p}}$ values obtained using DLS (Figure 5c). 

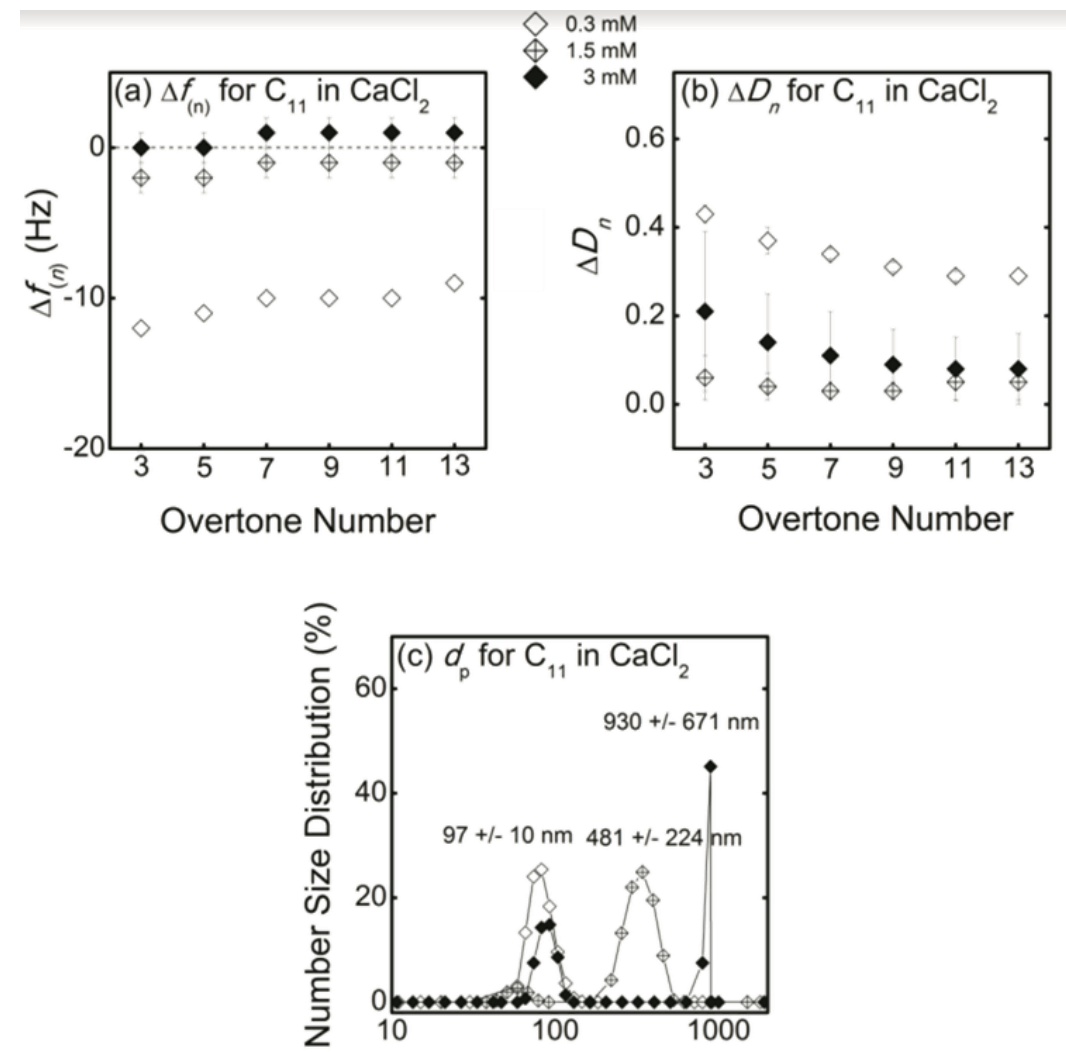

Hydrodynamic Diameter $(\mathrm{nm})$

Figure 5

At the lowest IS $\left(0.3 \mathrm{mM} \mathrm{CaCl}_{2}\right)$, Si-NCs capped with $\mathrm{C}_{11}$ are monodispersed $\left(d_{\mathrm{p}} \sim 97 \mathrm{~nm}\right)$, and in terms of frequency shifts, all the overtones $(n=3,5,7,9,11,13)$ exhibit "negative" responses, in agreement with inertial (i.e., Sauerbrey) loading (Olsson et al. 2012). As the IS increases to $1.5 \mathrm{mM}$ $\mathrm{CaCl}_{2}$, the Si-NCs experience aggregation and the suspensions become more polydisperse $\left(d_{\mathrm{p}}=481 \pm 224 \mathrm{~nm}\right)$. At this condition, values of $\Delta f_{\mathrm{n})}$ and $\Delta D_{\mathrm{n}}$ both decrease in comparison to those measured at lower IS. This can be explained by the fact that for particles approaching sizes resulting in a "coupled resonance" response, the bond strength (i.e. stiffness) influences the magnitude of the negative frequency shift. A stronger bond (e.g. by reduced electrostatic repulsion or $\mathrm{Ca}^{2+}$ bridging) reduces the frequency shifts per attached particle (Olsson et al. 2012; Pomorska et al. 2010). At $3 \mathrm{mM}$ 
$\mathrm{CaCl}_{2}$, the particle size becomes large enough $\left(d_{\mathrm{p}}=930 \pm 671 \mathrm{~nm}\right)$ to result in the typical "coupled resonance" response. At this condition, the deposition of the polydisperse Si-NCs results in mostly positive frequency shifts (Figure 5a). The higher overtones $(n=7,9,11,13)$ become positive as per "elastic loading", whereas lower overtones ( $n=3$ and 5 ) remain negative or close to zero as per "inertial loading". Also, we observe an increase in $\Delta D_{\mathrm{n}}$ when compared to the lower IS of $1.5 \mathrm{mM}$ (Figure $5 \mathrm{~b}$ ). As mentioned above, this is a clear indication that the traditional "Sauerbrey-type" response can gradually transform into a "coupled resonance"-type response as particle aggregation occurs. Applying this same analysis to all the experiments conducted in our study (Table 3), we note that this transition from elastic to inertial loading is likely linked to the mean size of the particle aggregates, where a critical average size $\left(d_{\mathrm{p}}-700 \mathrm{~nm}\right)$ appears to be the limit for this specific system.

\section{Conclusions}

Two complementary experimental techniques were used to investigate the deposition behavior of Si-NCs onto silica surfaces and provided useful insights into the role of particle surface cappings (carboxylic acids of different alkyl-chain lengths) and aggregate size on ENP deposition kinetics. Experiments conducted with packed columns show that the mobility of Si-NCs varies as the alkylchain length increases. The deposition behavior of particles coated with shorter chain lengths $\left(\mathrm{C}_{3}, \mathrm{C}_{7}\right)$ appears to be controlled by physicochemical filtration; namely, retention in the primary energy minimum, and upon aggregation, in a secondary energy well. Physical straining also contributes to the extent of retention of the aggregated $\mathrm{C}_{3}$ and $\mathrm{C}_{7} \mathrm{Si}-\mathrm{NC}$ suspensions in higher IS $\mathrm{KCl}$ and in $\mathrm{CaCl}_{2}$. Yet, the deposition behavior of Si-NCs capped with the longest alkyl chain $\left(\mathrm{C}_{11}\right)$ is controlled by 
electrosteric interactions. QCM-D provides further insight on nanoparticle deposition behavior, whereby the ratio of the two output parameters (frequency and dissipation) indicates how rigidly the nanoparticles are bound to the $\mathrm{SiO}_{2}$ surface. However, based on the obtained results, interpretation of ENP deposition behavior by QCM-D is limited by the presence of large aggregates $\left(d_{\mathrm{p}}-700 \mathrm{~nm}\right)$, which give rise to non-Sauerbrey behavior. Future studies of nanoparticle deposition using QCM-D should consider the response of all the overtones to adequately determine whether the acquired frequency shifts are proportional to the deposited mass. The combined approach used herein can be a useful method for investigating ENP-surface interaction phenomena in an effort to increase our knowledge of the roles that particle and collector surface coatings and water chemistry play in the transport and fate of ENPs in natural and engineered aquatic environments.

Supporting Information Available

Representative Si-NC breakthrough curves in $\mathrm{KCl}$ and $\mathrm{CaCl}_{2}$, comparative table of the deposition kinetics determined in sand columns and QCM-D, and representative ICP-OES measurements for Si-NCs capped with $\mathrm{C}_{3}$. 


\section{Acknowledgements}

The authors acknowledge the financial support of the Natural Sciences and Engineering Research Council of Canada (NSERC), the Canada Research Chairs program, les Fonds de recherche du Québec - Nature et Technologies, Environment Canada, and le Ministère du Développement économique, Innovation et Exportation (MDEIE). The authors also thank Ranjan Roy (McGill) for assistance with ICP-OES measurements. 
Author Disclosure Statement

No competing financial interests exist. 


\section{References}

Adamczyk Z, van de Ven TGM. (1981). Deposition of particles under external forces in laminar flow through parallel-plate and cylindrical channels. J. Colloid Interface Sci. 80,340-356.

Algar WR, Susumu K, Delehanty JB, Medintz IL. (2011). Semiconductor quantum dots in bioanalysis: Crossing the valley of death. Anal. Chem. 83,8826-8837.

Bell NC, Minelli C, Tompkins J, Stevens MM, Shard AG. (2012). Emerging techniques for submicrometer particle sizing applied to stöber silica. Langmuir 28,10860-10872.

Berglin M, Olsson ALJ, Elwing H. (2008). The interaction between model biomaterial coatings and nylon microparticles as measured with a quartz crystal microbalance with dissipation monitoring. Macromol. Biosci. 8,410-416.

Bradford SA, Torkzaban S, Walker SL. (2007). Coupling of physical and chemical mechanisms of colloid straining in saturated porous media. Water Res. 41,3012-3024.

Chen KL, Elimelech M. (2006). Aggregation and deposition kinetics of fullerene $\left(\mathrm{C}_{60}\right)$ nanoparticles. Langmuir 22,10994-11001.

Choi J, Zhang Q, Reipa V, Wang NS, Stratmeyer ME, Hitchins VM, Goering PL. (2009). Comparison of cytotoxic and inflammatory responses of photoluminescent silicon nanoparticles with silicon micronsized particles in RAW 264.7 macrophages. J. Appl. Toxicol. 29,52-60.

Clark RJ, Dang MKM, Veinot JGC. (2010). Exploration of organic acid chain length on water-soluble silicon quantum dot surfaces. Langmuir 26,15657-15664.

Domingos RF, Baalousha MA, Ju-Nam Y, Reid MM, Tufenkji N, Lead JR, Leppard GG, Wilkinson KJ. (2009). Characterizing manufactured nanoparticles in the environment: Multimethod determination of particle sizes. Environ. Sci. Technol. 43,7277-7284.

Dybwad GL. (1985). A sensitive new method for the determination of adhesive bonding between a particle and a substrate. J. Appl. Phys. 58,2789-2790.

Elimelech M, Gregory J, Jia X, R.A W. (1995). Particle deposition and aggregation - Measurement, modelling and simulation. (Butterworth-Heinemann). pp 448.

Fatisson J, Ghoshal S, Tufenkji N. (2010). Deposition of carboxymethylcellulose-coated zero-valent iron nanoparticles onto silica: Roles of solution chemistry and organic molecules. Langmuir 26,1283212840.

Fatisson M, Domingos RF, Wilkinson KJ, Tufenkji N. (2009). Deposition of $\mathrm{TiO}_{2}$ nanoparticles onto silica measured using a quartz crystal microbalance with dissipation monitoring. Langmuir 25,6062-6069.

Fujioka K, Hiruoka M, Sato K, Manabe N, Miyasaka R, Hanada S, Hoshino A, Tilley RD, Manome Y, Hirakuri K and others. (2008). Luminescent passive-oxidized silicon quantum dots as biological staining labels and their cytotoxicity effects at high concentration. Nanotechnology 19.

Gallego-Urrea JA, Tuoriniemi J, Hassellöv M. (2011). Applications of particle-tracking analysis to the determination of size distributions and concentrations of nanoparticles in environmental, biological and food samples. TrAC - Trends Anal. Chem. 30,473-483.

Hahn MW, Abadzic D, O'Melia CR. (2004). Aquasols: On the role of secondary minima. Environ. Sci. Technol. 38,5915-5924.

Hotze EM, Phenrat T, Lowry GV. (2010). Nanoparticle aggregation: Challenges to understanding transport and reactivity in the environment. J. Environ. Qual. 39,1909-1924.

Johannsmann D, Reviakine I, Richter RP. (2009). Dissipation in films of adsorbed nanospheres studied by quartz crystal microbalance (QCM). Anal. Chem. 81,8167-8176. 
Kanehira K, Banzai T, Ogino C, Shimizu N, Kubota Y, Sonezaki S. (2008). Properties of $\mathrm{TiO}_{2}$-polyacrylic acid dispersions with potential for molecular recognition. Colloids and Surf. B 64,10-15.

Klaine SJ, Alvarez PJJ, Batley GE, Fernandes TF, Handy RD, Lyon DY, Mahendra S, McLaughlin MJ, Lead JR. (2008). Nanomaterials in the environment: Behavior, fate, bioavailability, and effects. Environ. Toxicol. Chem. 27,1825-1851.

Lin S, Cheng Y, Liu J, Wiesner MR. (2012). Polymeric coatings on silver nanoparticles hinder autoaggregation but enhance attachment to uncoated surfaces. Langmuir 28,4178-4186.

Lin S, Wiesner MR. (2012). Deposition of aggregated nanoparticles - A theoretical and experimental study on the effect of aggregation state on the affinity between nanoparticles and a collector surface. Environ. Sci. Technol. 46,13270-13277.

Liu X, Chen G, Su C. (2012). Influence of collector surface composition and water chemistry on the deposition of cerium dioxide nanoparticles: QCM-D and column experiment approaches. Environ. Sci. Technol. 46,6681-6688.

Mitzel MR, Tufenkji N. (2014). Transport of Industrial PVP-Stabilized Silver Nanoparticles in Saturated Quartz Sand Coated with Pseudomonas aeruginosa PAO1 Biofilm of Variable Age. Environ. Sci. Technol. 48,2715-2723.

O'Farrell N, Houlton A, Horrocks BR. (2006). Silicon nanoparticles: applications in cell biology and medicine. Int. J. Nanomed. 1,451-472.

Ohshima H. (1994). A simple expression for Henry's function for the retardation effect in electrophoresis of spherical colloidal particles. J. Colloid Interface Sci. 168,269-271.

Olsson ALJ, Quevedo IR, He D, Basnet M, Tufenkji N. (2013). Using the quartz crystal microbalance with dissipation monitoring to evaluate the size of nanoparticles deposited on surfaces. ACS Nano 7,78337843.

Olsson ALJ, Van Der Mei HC, Johannsmann D, Busscher HJ, Sharma PK. (2012). Probing colloid-substratum contact stiffness by acoustic sensing in a liquid phase. Anal. Chem. 84,4504-4512.

Park J-H, Gu L, von Maltzahn G, Ruoslahti E, Bhatia SN, Sailor MJ. (2009). Biodegradable luminescent porous silicon nanoparticles for in vivo applications. Nat Mater 8,331-336.

Pelley AJ, Tufenkji N. (2008). Effect of particle size and natural organic matter on the migration of nano- and microscale latex particles in saturated porous media. J. Colloid Interface Sci. 321,74-83.

Petosa AR, Brennan SJ, Rajput F, Tufenkji N. (2012). Transport of two metal oxide nanoparticles in saturated granular porous media: Role of water chemistry and particle coating. Water Res. 46,1273-1285.

Petosa AR, Jaisi DP, Quevedo IR, Elimelech M, Tufenkji N. (2010). Aggregation and deposition of engineered nanomaterials in aquatic environments: Role of physicochemical interactions. Environ. Sci. Technol. 44,6532-6549.

Phenrat T, Song JE, Cisneros CM, Schoenfelder DP, Tilton RD, Lowry GV. (2010). Estimating attachment of nano- and submicrometer-particles coated with organic macromolecules in porous media: Development of an empirical model. Environ. Sci. Technol. 44,4531-4538.

Pomorska A, Shchukin D, Hammond R, Cooper MA, Grundmeier G, Johannsmann D. (2010). Positive frequency shifts observed upon adsorbing micron-sized solid objects to a quartz crystal microbalance from the liquid phase. Anal. Chem. 82,2237-2242.

Quevedo IR, Olsson ALJ, Tufenkji N. (2013). Deposition kinetics of quantum dots and polystyrene latex nanoparticles onto alumina: Role of water chemistry and particle coating. Environ. Sci. Technol. 47,2212-2220.

Quevedo IR, Tufenkji N. (2009). Influence of solution chemistry on the deposition and detachment kinetics of a CdTe quantum dot examined using a quartz crystal microbalance. Environ. Sci. Technol. 43,31763182 . 
Quevedo IR, Tufenkji N. (2012). Mobility of functionalized quantum dots and a model polystyrene nanoparticle in saturated quartz sand and loamy sand. Environ. Sci. Technol. 46,4449-4457.

Raychoudhury T, Tufenkji N, Ghoshal S. (2012). Aggregation and deposition kinetics of carboxymethyl cellulose-modified zero-valent iron nanoparticles in porous media. Water Res. 46,1735-1744.

Roco M, Mirkin C, Hersam M. (2011). Nanotechnology research directions for societal needs in 2020: summary of international study. J. Nanopart. Res. 13,897-919.

Ruizendaal L, Bhattacharjee S, Pournazari K, Rosso-Vasic M, De Haan LHJ, Alink GM, Marcelis ATM, Zuilhof H. (2009). Synthesis and cytotoxicity of silicon nanoparticles with covalently attached organic monolayers. Nanotoxicology 3,339-347.

Sakulchaicharoen N, O'Carroll DM, Herrera JE. (2010). Enhanced stability and dechlorination activity of presynthesis stabilized nanoscale FePd particles. J. Contam. Hydrol. 118,117-127.

Saleh N, Kim H-J, Phenrat T, Matyjaszewski K, Tilton RD, Lowry GV. (2008). Ionic strength and composition affect the mobility of surface-modified $\mathrm{Fe}^{0}$ nanoparticles in water-saturated sand columns. Environ. Sci. Technol. 42,3349-3355.

Sauerbrey GZ. (1959). Verwendung von. Schwingquarzen zur wiigung dunner. Schichten und zur mikrowägung. Z.Phys 155,206-222.

Tufenkji N, Elimelech M. (2004). Correlation equation for predicting single-collector efficiency in physicochemical filtration in saturated porous media. Environ. Sci. Technol. 38,529-536.

Tufenkji N, Miller GF, Ryan JN, Harvey RW, Elimelech M. (2004). Transport of Cryptosporidium oocysts in porous media: Role of straining and physicochemical filtration. Environ. Sci. Technol. 38,5932-5938.

Vogel R, Willmott G, Kozak D, Roberts GS, Anderson W, Groenewegen L, Glossop B, Barnett A, Turner A, Trau M. (2011). Quantitative sizing of nano/microparticles with a tunable elastomeric pore sensor. Anal. Chem. 83,3499-3506.

Westerhoff PK, Kiser A, Hristovski K. (2013). Nanomaterial removal and transformation during biological wastewater treatment. Environ. Eng. Sci. 30,109-117.

Yao KM, Habibian MT, O'Melia CR. (1971). Water and waste water filtration: Concepts and applications. Environ. Sci. Technol. 5,1105-1112. 